\title{
Initiating oral breathing in response to nasal loading: asthmatics versus healthy subjects
}

\author{
M. Hallani*,\#, J.R. Wheatley,"\# and T.C. Amis*,"
}

ABSTRACT: Factors influencing nasal versus oral breathing in asthmatics are not well understood. The current authors hypothesised that asthmatic subjects have enhanced perception of nasal threshold loads, and switch from nasal to oral breathing at a lower load than healthy subjects.

In total, 15 mild asthmatic and 20 healthy control subjects breathed nasally via an inspiratory threshold loading device. Nasal loading was progressively increased until subjects switched to oral breathing. Load perception at switching was rated using a Borg scale. Nasal resistance was measured using posterior rhinomanometry. The protocol was repeated before and after nasal decongestant administration in subgroups of 10 healthy control and six asthmatic subjects.

Inspiratory nasal resistance was within normal limits for most subjects and was not significantly different between asthmatics and healthy controls. Compared with controls, asthmatics switched to oral breathing at a significantly lower nasal load but rated "difficulty breathing in" at the same level. Decongestant significantly lowered nasal resistance but did not change the nasal load initiating switching in either subgroup.

Enhanced perception of nasal loading may trigger increased oral breathing in asthmatics, potentially enhancing exposure to nonconditioned inhaled gas and contributing to the occurrence and/or severity of bronchoconstrictive exacerbations.

KEYWORDS: Airway physiology, asthma, perception, upper airway loading

$\mathbf{T}$ here are few studies that have examined route of breathing (i.e. nasal versus oral breathing) in asthmatics. One study demonstrated that during an asthma attack patients breathed oronasally, but changed to exclusive nasal breathing post-recovery [1]. The breathing route may be important in asthma, since inspiration via the mouth bypasses the warming, humidification and filtering functions of the nasal passages, thus potentially exposing the lower airways to nonconditioned inhaled gas. In support of this, mouth breathing has been demonstrated to potentiate exercise-induced asthma, whereas nasal breathing is protective [2]. Despite considerable research on the bronchoconstrictive pathways associated with oral inhalation of cold, dry gas $[3,4]$, the underlying mechanisms that determine oral versus nasal breathing in asthmatics have received little attention.

During exercise, healthy subjects switch from nasal to oronasal breathing (switching point) at a minute ventilation that is related to the magnitude of the work of nasal breathing and/or the perceived level of exertion [5-8]. However, during bronchoconstrictive episodes asthmatic subjects may reach work of breathing levels that trigger a switch to the potentially lower resistance oral pathway without the necessity for exercise. Asthmatics also often suffer from concomitant nasal disease [9], resulting in high nasal resistance, further contributing to the potential for an early switch to oral breathing. In addition, studies have identified altered load perception in asthmatics [10-12], raising the potential for underlying modification of breathing route responses to imposed internal or external loads through the perceived rather than the actual load.

Resting breathing route switching in response to respiratory loads has not been previously studied in asthmatics or in healthy subjects. In the present study of both mild asthmatic and nonasthmatic control subjects, the current authors determined: 1) the magnitude of externally applied nasal inspiratory threshold loads associated with the onset of oral breathing at rest; 2) subject perception of the level of "difficulty breathing in" at the onset of oral breathing; and 3) the ability to modify subject breathing route responses to nasal loading using topical nasal decongestant.
AFFILIATIONS

*Ludwig Engel Centre for Respiratory Research, and

\#Dept of Respiratory Medicine, Westmead Hospital, Wentworthville, NSW, Australia

CORRESPONDENCE

T.C. Amis

Dept of Respiratory Research

Westmead Hospital

PO Box 533

Wentworthville

2145 NSW

Australia

Fax: 61298457286

E-mail: terence_amis@

wmi.usyd.edu.au

Received:

January 032007

Accepted after revision:

November 072007

SUPPORT STATEMENT

This work was funded by the Australian Postgraduate Award, Westmead Millennium Foundation (Wentworthville, NSW, Australia) and National Health and Medical Research Council of Australia.

STATEMENT OF INTEREST

None declared.

European Respiratory Journal

Print ISSN 0903-1936

Online ISSN 1399-3003 


\section{METHODS}

\section{Subjects}

In total, 15 nonsmoking, mild, currently asymptomatic, asthmatic subjects were studied (13 females, two males; age (mean \pm SEM) $35.9 \pm 3.4$ yrs; body mass index (BMI) $25.4 \pm 4.2 \mathrm{~kg} \cdot \mathrm{m}^{-2}$ ), each of whom reported a medical diagnosis of asthma. All subjects reported wheezing and/or cough at least once per week and all used inhaled reliever medication ( $\beta$-adrenergic agonist), but none were currently using preventative medication (inhaled corticosteroids). At the time of the study, subjects had not used bronchodilators in the previous $24 \mathrm{~h}$, and all were free of symptoms of respiratory tract infection for $\geqslant 4$ weeks. Subjects with chronic nasal and/ or sinus disease were included provided they had not used inhaled nasal corticosteroid medications for $\geqslant 4$ weeks, and short-acting nasal decongestants for $\geqslant 24 \mathrm{~h}$.

In addition, 20 nonsmoking individuals (controls: 12 females, eight males; age $27.1 \pm 2.4 \mathrm{yrs} ; \mathrm{BMI} 23.5 \pm 3.2 \mathrm{~kg} \cdot \mathrm{m}^{-2}$ ), each reporting no history of asthma or any nasal disease, and no respiratory symptoms for $\geqslant 4$ weeks, were also studied.

All subjects completed a screening questionnaire regarding anthropometric data and medical history relating to upper and lower airway disease, surgery and current medications. All were instructed not to ingest food and drinks containing caffeine for $\geqslant 4 \mathrm{~h}$ prior to the study. Subjects gave written, informed consent but were kept naïve as to the specific purpose of the study. The protocol was approved by the Human Ethics Committee of the Western Sydney Area Health Service.

\section{Experimental set-up}

A forced expiratory volume in one second (FEV1) measurement (best of three reproducible manoeuvres) was obtained from each subject at the beginning of the study (Autospirometer AS-800; Minato Medical Science, Osaka, Japan).

Graded nasal inspiratory threshold loads were applied using an experimental set-up (fig. 1) modified from that designed by CHEN et al. [13]. Briefly, subjects breathed via a dual compartment face mask (Hans Rudolph Inc., Kansas City, MO, USA) sealed to the face with a glycerine-based polymer gel (Ultimate Seal; Hans Rudolph Inc.). Nasal and oral airflows were measured with separate pneumotachographs (Fleisch \#2; Fleisch, Lausanne, Switzerland). Pressures at the nose $(P \mathrm{~N})$ and mouth were monitored with separate pressure transducers ( $\pm 100 \mathrm{cmH}_{2} \mathrm{O}$; Celesco, Chatsworth, CA, USA). The oral pathway pneumotachograph was open to room air, while the nasal pathway pneumotachograph was connected to a nonrebreathing valve such that expiratory airflow was vented to the atmosphere. The inspiratory arm of the non-rebreathing valve was connected to a three-way tap, allowing nasal inspiration to occur directly from room air or via an inspiratory threshold loading device. There was no leakage detected between the nasal and oral compartments when subjects were instructed to breathe via the nose only.

The inspiratory threshold pressure (PIT) loading device consisted of a plastic pipe with holes in the side of different diameters (2-21 mm; fig. 1). Graded negative pressure was generated within the chamber (PIT) via an adjustable vacuum source and by occluding/unoccluding combinations of the side holes. In this manner, a predetermined PIT could be

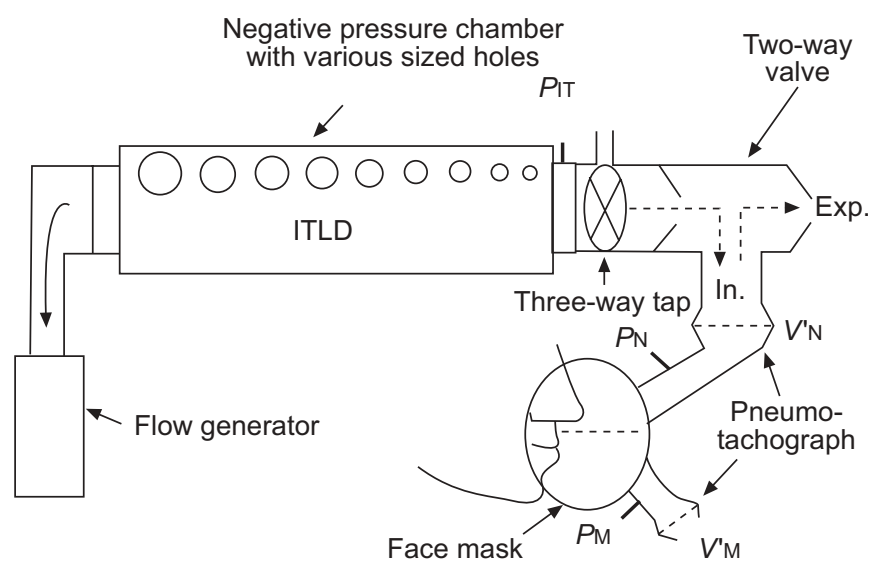

FIGURE 1. Schematic diagram of experimental set-up. Subjects breathed via a dual-compartment face mask with the nasal compartment attached to a two-way valve, the inspiratory port of which was connected via a three-way tap to the inspiratory threshold loading device (ITLD). Arrows indicate the direction of airflow. $P$ N: nasal pressure; $P$ M: mouth pressure; $V^{\prime} \mathrm{N}$ : nasal airflow; $V^{\prime} \mathrm{M}$ : oral airflow; $\mathrm{PIT}_{\mathrm{T}}$ inspiratory threshold pressure, required to open the inspiratory port of two-way valve and pre-set by selectively blocking known concentrations of holes in the ITLD; In.: inspiration; Exp.: expiration.

generated. A pressure transducer $\left( \pm 100 \mathrm{cmH}_{2} \mathrm{O}\right.$; Celesco) monitored PIT adjacent to the inspiratory valve. Using this arrangement, inspiration could only occur when the subject had generated a sufficiently negative $P \mathrm{~N}$ (the nasal load) to overcome PIT, thus allowing the inspiratory valve to open.

To reduce visual cues, the experimental set-up was screened from the subject, with only the face mask being visible. To reduce auditory cues during the application of nasal loads, subjects listened to music via headphones.

Data were recorded, digitised at $400 \mathrm{~Hz}$ (Maclab 1/16S; AD Instruments Pty Ltd, Castle Hill, Australia) and stored on a computer for later analysis (Chart software V2.6.1/s; AD Instruments Pty Ltd).

\section{Perception measurement}

Subjects rated their perception of difficulty breathing using a modified Borg scale (table 1) [14].

\section{Protocol}

Following measurement of FEV1, subjects were fitted with the face mask and 2 min of quiet tidal breathing data were obtained with the inspiratory arm of the non-rebreathing valve open to room air. Subjects were free to spontaneously choose the breathing route. At the end of this run-in period, subjects were instructed to commence breathing through their nose only. They were then given the following instruction: "If at some stage you feel it would be comfortable to breathe through your mouth, then open your mouth and breathe through the mask on your face."

The three-way tap was then positioned to connect subjects to the inspiratory threshold loading device with a starting PIT of $-0.35 \mathrm{cmH}_{2} \mathrm{O}$. A "switch" to oral breathing was defined by the occurrence of at least five oral or oronasal breaths within the next 10 consecutive breaths following each load application. If there was no switch to oral breathing, the next PIT level was 


\begin{tabular}{l} 
TABLE 1 Modified Borg scale used to evaluate perception \\
of "difficulty breathing in" \\
How much difficulty did you notice breathing in? \\
0 Not at all \\
0.5 Very, very slight (just noticeable) \\
1 Very slight \\
2 Slight (light) \\
3 Moderate \\
4 Somewhat severe \\
5 Severe (heavy) \\
6 \\
7 Very severe \\
8 \\
9 \\
10 Very, very severe (almost maximal) \\
- Maximal \\
\hline
\end{tabular}

applied. In this manner, the PIT was gradually decreased in $\sim 1.25 \mathrm{cmH}_{2} \mathrm{O}$ steps until a switch was detected. The inspiratory threshold nasal load at which subjects switched to oral breathing was measured as the peak inspiratory $P_{\mathrm{N}}$ for the nasal-only breath that immediately preceded the first oral or oronasal breath in the five-breath switch, confirming sequence (fig. 2).

Once a switch had occurred, the subject was instructed to return to nasal breathing while the PIT level was maintained. Immediately following the first nasal-only breath, subjects were asked to rate their perception of difficulty breathing in by pointing to their chosen score on a hard copy of the Borg scale. No marks were made on the Borg scale sheet; thus, subjects were unable to view any previously chosen score. Once a perception score was recorded, the PIT was returned to the starting level and, after a 2-min rest period, the process was repeated until a total of three runs had been performed.

\section{Measurement of nasal resistance}

At the end of the protocol mentioned previously, a separate experimental set-up for standard posterior rhinomanometry was used to obtain pressure-flow data for the nasal passages [15]. Nasal resistance was then calculated at $0.4 \mathrm{~L} \cdot \mathrm{s}^{-1}$ of inspiratory airflow. Technically acceptable measurements of nasal resistance were obtained in 10 of the 15 asthmatic subjects and 13 of the 20 control subjects.

\section{Nasal resistance/nasal decongestant studies}

Following an acceptable measurement of baseline nasal resistance, topical nasal decongestant (two sprays of $0.5 \mathrm{mg} \cdot \mathrm{mL}^{-1}$ oxymetazoline hydrochloride in each nostril; Schering-Plough, Kenilworth, NJ, USA) was then administered, followed $15 \mathrm{~min}$ later by a second posterior rhinomanometry measurement. Technically acceptable nasal resistance measurements were obtained for subgroups of 10 control (two males, eight females; age $26.8 \pm 2.7 \mathrm{yrs}$ ) and six asthmatic (all females; age $41.0 \pm 5.1$ yrs $)$ subjects. Switching load and perception data were then obtained as described previously.

\section{Data analysis}

Data from the three switching runs were averaged to obtain individual subject values that were then pooled to obtain

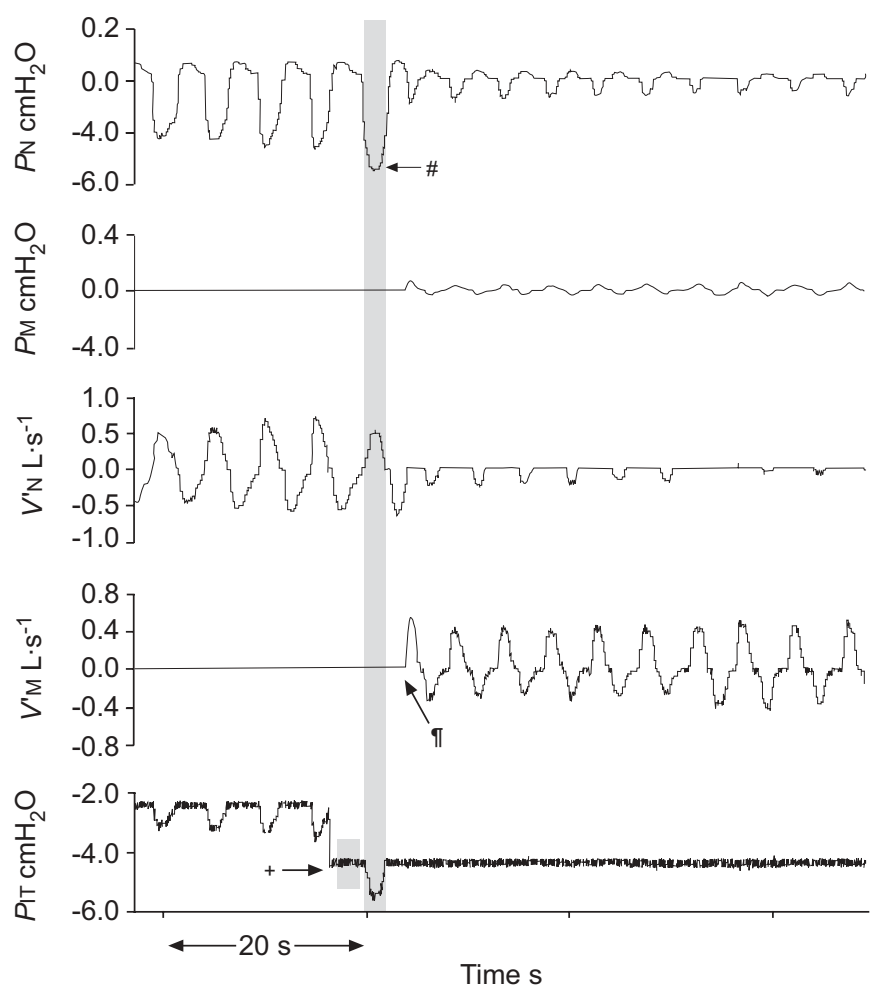

FIGURE 2. Representative tracing of nasal $(P N)$ and mouth $(P M)$ pressures, and nasal $\left(V^{\prime} N\right)$ and oral $\left(V^{\prime} M\right)$ airflows in an asthmatic subject. Inspiratory flow is in the upward direction. Inspiratory threshold pressure (PIT) change $\left(^{+}\right)$triggers the onset of mouth breathing $\left(^{\circledR}\right)$. The peak inspiratory $P_{N}$ value for the last nasal inspiration prior to the onset of oral breathing $\left({ }^{\#}\right)$ was defined as the nasal inspiratory threshold switching load.

overall group mean \pm SEM values. These values were calculated for the main asthmatic and control groups, and for both the pre- and post-nasal decongestant conditions for the two subgroups. Comparisons were made using paired and unpaired t-tests for single comparisons and repeated measures of ANOVA with Bonferroni's multiple comparison test (posthoc) for multiple comparisons. Linear regression analysis was used to test for correlations. A Chi-squared test with Yates' correction for continuity was used to compare resting breathing route usage with and without nasal decongestant administration. A p-value $<0.05$ was considered significant.

\section{RESULTS}

\section{Main group studies}

In this section, data are presented from the main groups of 15 asthmatic and 20 healthy control subjects. The mean age of the two main groups was not significantly different $(p>0.05)$. Group data are summarised in table 2.

\section{Spirometry}

For both the control and asthmatic groups, FEV1 was $>70 \%$ predicted in all subjects. For the two groups, mean \pm SEM FEV 1 values tended to be higher in the control subjects $(97.8 \pm 4.5 \%$ pred) than in the asthmatics $(86.7 \pm 3.7 \%$ pred) but this difference did not reach significance $(\mathrm{p}>0.08)$. 


\begin{tabular}{|c|c|c|c|}
\hline \multirow[t]{2}{*}{ TABLE 2} & \multicolumn{3}{|c|}{$\begin{array}{l}\text { Group data for nasal resistance, switching load } \\
\text { and perception rating in the main and subgroup } \\
\text { studies }\end{array}$} \\
\hline & & Controls & Asthmatics \\
\hline \multicolumn{4}{|l|}{ Main group } \\
\hline Nasal resis & ince $\mathrm{cmH}_{2} \mathrm{O} \cdot \mathrm{L} \cdot \mathrm{s}^{-1}$ & $2.6 \pm 0.3(13)$ & $3.3 \pm 0.7(10)$ \\
\hline Switching I & $\mathrm{ad} \mathrm{cmH}_{2} \mathrm{O}$ & $-8.1 \pm 1.4(20)$ & $-4.2 \pm 0.5^{\star}(15)$ \\
\hline Perception & ating $A U$ & $1.9 \pm 0.3(20)$ & $2.2 \pm 0.4(15)$ \\
\hline \multicolumn{4}{|c|}{ Subgroup data } \\
\hline Subjects $\mathrm{n}$ & & 10 & 6 \\
\hline \multicolumn{4}{|c|}{ Nasal resistance $\mathrm{cmH}_{2} \mathrm{O} \cdot \mathrm{L} \cdot \mathrm{S}^{-1}$} \\
\hline Pre-nasa & decongestant & $2.8 \pm 0.3$ & $4.9 \pm 0.8^{*}$ \\
\hline Post-nas & decongestant & $1.6 \pm 0.3^{\#}$ & $2.3 \pm 0.4^{\#}$ \\
\hline \multicolumn{4}{|c|}{ Switching load $\mathrm{cmH}_{2} \mathrm{O}$} \\
\hline Pre-nasa & decongestant & $-7.7 \pm 1.6$ & $-3.5 \pm 1.5^{\star}$ \\
\hline Post-nas & decongestant & $-8.9 \pm 1.8$ & $-3.9 \pm 1.8^{*}$ \\
\hline \multicolumn{4}{|c|}{ Perception rating $\mathrm{AU}$} \\
\hline Pre-nasa & decongestant & $2.6 \pm 0.3$ & $1.8 \pm 0.6$ \\
\hline Post-nas & decongestant & $2.0 \pm 0.3$ & $1.6 \pm 0.5$ \\
\hline
\end{tabular}

\section{Nasal resistance}

Inspiratory nasal resistance values ranged $0.9-6.4 \mathrm{cmH}_{2} \mathrm{O} \cdot \mathrm{L} \cdot \mathrm{s}^{-1}$ in asthmatic subjects and $1.7-4.9 \mathrm{cmH} \mathrm{H}_{2} \mathrm{O} \cdot \mathrm{L} \cdot \mathrm{s}^{-1}$ in control subjects. When the group data were examined, there was no significant difference in baseline inspiratory nasal resistance between the asthmatic and control groups (table 2).

\section{Switching load}

A progressively increasing nasal inspiratory threshold load eventually initiated oral breathing in all asthmatic and healthy control subjects. The switching load (i.e. $P \mathrm{~N}$ ) ranged $-2.2--29.3$ $\mathrm{cmH}_{2} \mathrm{O}$ in control subjects and $-0.9--8.5 \mathrm{cmH}_{2} \mathrm{O}$ in asthmatic subjects. Group median (interquartile range) values for intrasubject coefficients of variation for switching load across the three runs in each subject were $21.2(10.7-28.5) \%$ in the controls and $20.3(9.1-25.2) \%$ in the asthmatics.

When the group data were examined, the level of load initiating switching for asthmatic subjects was only $\sim 50 \%$ of that measured in the healthy control subjects (i.e. PN values were significantly less negative in asthmatics compared with controls; table 2, fig. 3). There was no significant correlation between the magnitude of the nasal load initiating switching and baseline nasal resistance values within the asthmatic group $(\mathrm{r}=0.3, \mathrm{p}>0.3)$. Within the control group, however, there was a weak but significant positive correlation between these two variables $(r=0.5, p<0.05)$.

\section{Perception of difficulty breathing in}

At the nasal load initiating switching, the perception of the difficulty breathing in was rated in both the asthmatic and the healthy control groups in the "slight" range. Perception ratings ranged $0.0-1.5 \mathrm{AU}$ in control subjects and 0.5-4.0 AU in

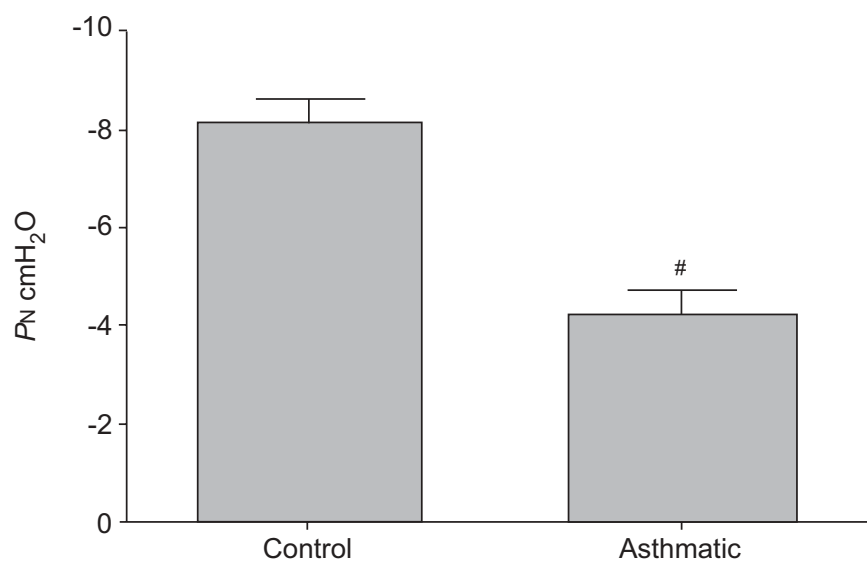

FIGURE 3. Group mean data for the nasal inspiratory threshold load $(P N)$ initiating a switch to oral breathing in control and asthmatic subjects. The bars represent SEM. ${ }^{*}: \mathrm{p}<0.03$.

asthmatic subjects. Intra-subject coefficients of variation ranged $0.3-5.2 \%$ in controls and $2.2-2.3 \%$ in asthmatics. When the group data were examined, there was no significant difference in perception ratings between the asthmatic and control groups (table 2).

\section{Route of breathing at rest: run-in period}

During the run-in period, oronasal breathing was recorded in $47 \%$ of asthmatic subjects and $45 \%$ of control subjects. All other subjects breathed exclusively via the nose. Nasal resistance values for subjects breathing oronasally during the run-in period were not significantly different to those for subjects breathing exclusively via the nose for both the asthmatic $\left(3.0 \pm 1.2\right.$ versus $4.2 \pm 0.9 \mathrm{cmH}_{2} \mathrm{O} \cdot \mathrm{L} \cdot \mathrm{s}^{-1}$, respectively; $\left.\mathrm{p}>0.3\right)$ and control groups $\left(2.5 \pm 0.3\right.$ versus $3.1 \pm 0.6 \mathrm{cmH}_{2} \mathrm{O} \cdot \mathrm{L} \cdot \mathrm{s}^{-1}$, respectively; $\mathrm{p}>0.3)$.

Switching load values for subjects breathing oronasally during the run-in period were not significantly different to those for subjects breathing exclusively via the nose for both the asthmatic $\left(-3.4 \pm 0.6\right.$ versus $-5.0 \pm 0.7 \mathrm{cmH}_{2} \mathrm{O}$, respectively; $\mathrm{p}>0.06$.) and control groups $\left(-7.5 \pm 1.8\right.$ versus $-8.7 \pm 2.3 \mathrm{cmH}_{2} \mathrm{O}$, respectively; $\mathrm{p}>0.35)$. Perception ratings for subjects breathing oronasally during the run-in period were also not significantly different to those for subjects breathing exclusively via the nose for both the asthmatic ( $2.4 \pm 0.8$ versus $2.4 \pm 0.6 \mathrm{AU}$, respectively; $\mathrm{p}>0.5)$ and control groups ( $1.6 \pm 1.1$ versus $0.8 \pm 0.3 \mathrm{AU}$, respectively; $\mathrm{p}>0.3$ ).

\section{Nasal decongestant subgroup studies}

In this section, data are presented for six asthmatic and 10 healthy control subjects for whom technically acceptable measurements of nasal resistance were obtained both before and after administration of topical nasal decongestant (table 2). The asthmatic group was significantly older than the control group $(\mathrm{p}<0.02)$

Nasal resistance

With administration of topical nasal decongestant, subgroup mean values for nasal resistance fell significantly in both the asthmatic and control subgroups (table 2). 
Route of breathing at rest: run-in period

Although topical nasal decongestant reduced the prevalence of resting oronasal breathing to $\sim 25 \%$ in both the asthmatic and control subgroups, this apparent change did not achieve statistical significance (asthmatic subgroup: $\mathrm{p}>0.1$; control subgroup: $\mathrm{p}>0.4$ ).

\section{Switching load}

A progressively increasing nasal load initiated oral breathing in all asthmatic and control subjects for the post-decongestant conditions. The nasal load initiating oral breathing for asthmatic subjects was significantly lower than that for healthy control subjects for both the pre- and post-decongestant conditions (table 2). However, for both asthmatics and controls, postdecongestant nasal load values were not significantly different to pre-decongestant values (table 2). There was no significant correlation between nasal load magnitude initiating switching and nasal resistance values within the asthmatic subgroup for either pre-decongestant $(\mathrm{r}=0.07, \mathrm{p}>0.8)$ or post-decongestant $(r=0.2, p>0.6)$ conditions. However, for the healthy control subgroup a significant correlation existed for the pre-decongestant condition $(r=0.7, p<0.02)$ but not for the post-decongestant condition $(\mathrm{r}=0.2, \mathrm{p}>0.5)$.

\section{Perception of difficulty breathing in}

Following nasal decongestant, both the asthmatic and the healthy control subgroups continued to rate their perception of the difficulty breathing in at the load initiating switching in the slight range. Post-decongestant perception ratings were not significantly different to pre-decongestant values for both the control and asthmatic subgroups (table 2). There was also no significant difference for before and after decongestant values between the two subgroups ( $p>0.1)$.

\section{DISCUSSION}

In the present study of breathing routes in mild asymptomatic asthmatic and healthy control subjects, all with inspiratory nasal airflow resistance values $<6.5 \mathrm{cmH} \mathrm{H}_{2} \mathrm{O} \cdot \mathrm{L} \cdot \mathrm{s}^{-1}$, progressively increasing the magnitude of nasal inspiratory threshold loading resulted in a switch from exclusively nasal to oronasal breathing in all subjects. Compared with control subjects, asthmatic subjects switched at a significantly lower applied load but at a similar level of perceived breathing difficulty. Reducing nasal resistance using topical nasal decongestant did not alter the magnitude of the switching load.

\section{Age and sex}

Asthmatic and control subjects were not individually matched for age and sex but group mean age was not significantly different between the asthmatic and control subjects for the main group. However, the asthmatic decongestant subgroup was older than the control decongestant subgroup. Additionally, the main group and subgroups contained a majority of females. Consequently, it seems unlikely that subject age is an influence on the study results, at least for the main group, but the current findings may be more reflective of responses for females than for males.

\section{Nasal airflow resistance}

In the present study, pre-decongestant nasal resistance values for the asthmatic and control subjects were not significantly different and were both largely within the reported range for normal subjects [16]. Thus, although $\sim 80 \%$ of asthmatics suffer from nasal pathology [9] and have high nasal resistance values [17], this was not the case with the mild asthmatic group recruited for the present study. Consequently, the current findings apply to asthmatics with essentially normal nasal airflow resistance and may or may not extend to those with greater degrees of nasal obstruction.

For the control group, subjects with higher baseline nasal resistance values (although within the normal range), tolerated higher loads before initiating oral breathing. This relationship was not present in the asthmatic subjects. The mechanisms associated with this relationship in healthy subjects, and its disruption in asthma, require further investigation, but the current authors speculate that the sensory processing of respiratory loading may be modified by the chronic level of the loads associated with the disease processes of chronic asthma and/or allergic rhinitis.

When topical nasal decongestant was administered, nasal resistance decreased to $<3.0 \mathrm{cmH}_{2} \mathrm{O} \cdot \mathrm{L} \cdot \mathrm{s}^{-1}$ in both the asthmatic and healthy control subgroups but the nasal load initiating switching was not significantly different. In addition, the relationship between nasal resistance and the switching load, present in the control subgroup prior to decongestant administration, was now absent. Thus, within the range of nasal resistance values encountered in the present study, the onset of oral breathing in response to external nasal inspiratory threshold loading does not appear to be greatly influenced by baseline nasal resistance, although control subjects tend to tolerate higher loads before switching if their baseline nasal resistance is relatively higher (although still within the normal range). It should be noted, however, that the number of subjects in the present study is relatively small and the range of nasal resistance values is both small and largely within the normal range. Consequently, the current correlative-based findings need to be interpreted with caution.

\section{Nasal inspiratory threshold loading}

Application of even a relatively small load $\left(\sim 2.5 \mathrm{cmH}_{2} \mathrm{O} \cdot \mathrm{L} \cdot \mathrm{s}^{-1}\right)$ to the nares of healthy subjects has been shown to increase inspiratory time and decrease minute ventilation [18]. Moreover, nasal route loading is associated with a larger reduction in ventilation than when the same load is applied at the mouth [19]. Given this impact on ventilation, switching to mouth breathing offers subjects the ability to maintain ventilatory levels with a potentially reduced work of breathing. The present study is the first to quantify the relationship between nasal inspiratory threshold load magnitude and the onset of oronasal breathing at rest in either asthmatic or healthy subjects. Compared with control subjects, asthmatic subjects switched at a significantly lower applied load but at a similar level of perceived breathing difficulty. Thus, asthmatics have an increased propensity to switch to oronasal breathing when faced with an increase in nasal load than control subjects.

\section{Breathing route at rest: run-in period}

During resting tidal breathing, it is generally reported that healthy subjects breathe exclusively via the nose [20]. One study has associated an increased nasal resistance with a tendency to use oral route breathing [21]; however, switching 
behaviour at rest has only been previously investigated in lambs [22], where complete nasal obstruction was required to induce oral breathing. The only study investigating breathing routes in asthmatic subjects demonstrated that, during an acute exacerbation of asthma, subjects breathed oronasally but switched to nasal breathing post-recovery [1]. In the present study, there was no difference in resting breathing route between mild asymptomatic asthmatics and control subjects. Indeed, just under half of both the healthy and asthmatic subjects had oronasal breathing at rest, with no significant change in resting breathing route after the administration of a topical nasal decongestant. Nasal pathway apparatus resistance and the mask itself may have influenced spontaneous breathing during the run-in; however, there was no oral breathing at the commencement of load application (i.e. all subjects were breathing nasally as instructed) ensuring uniform starting conditions for the loading challenge.

In the present study, nasal resistance values were not significantly different between those breathing oronasally during the run-in and those breathing nasally. Consequently, nasal resistance does not appear to have influenced spontaneous breathing route. In turn, spontaneous breathing route did not influence the nasal load required to initiate oral breathing. These findings are, perhaps, not surprising since nasal resistance values in the subjects were all relatively normal.

\section{Mechanisms determining breathing route}

Although the mechanisms that govern the use of nasal versus oral breathing remain uncertain, the level of work/power during nasal-only breathing is thought to be a key trigger for the onset of mouth breathing, at least during exercise [6]. In humans, nasal temperature and/or pressure receptors [23-25] may play an important role in controlling shifts in breathing route. Furthermore, with mild-to-moderate inspiratory loading, mechanoreceptors in the lower airways are almost certainly stimulated [26], most likely resulting in feedback to higher centres in the brain. In the present study, the nasal load initiating switching was measured as the peak inspiratory nasal pressure at the onset of oral breathing. Thus, the current authors speculate that pressure receptors in the nasal vestibule may play a role in the switch from nose to mouth breathing in response to an externally applied nasal load. This is supported by the failure of nasal decongestant to change the nasal load value initiating switching, despite causing a reduction in nasal resistance (and hence total load presented to receptors in the upper and lower airways and chest wall).

\section{Perception of nasal inspiratory threshold load magnitude}

In the present study, both asthmatic and control subjects used a Borg scale rating of $\sim 2$ AU slight (light) to describe their perception of difficulty breathing in at the nasal load initiating switching. Consequently, it appears that when the opportunity to switch to oral breathing exists, neither control nor asthmatic subjects will tolerate even small nasal loads. However, since the asthmatic and healthy subject groups switched at a similar perception level, but at different load magnitudes, it seems that an asthmatic's perception of "slight difficulty breathing in" is altered from that of a nonasthmatic. Subjective perception of the degree of difficulty breathing in against a nasal airway that is being progressively loaded may be an important factor in determining the switch to oronasal route breathing. In asthmatic subjects, heightened perception of breathing difficulty may allow a perception trigger level for oral breathing to be reached at a lower actual load than is the case for control subjects.

The current finding suggesting that mild asymptomatic asthmatic subjects may have heightened perception to added external nasal loads has not been previously reported and contrasts with the results of studies investigating lower airway load perception. ECKERT et al. [27] and JULIUs et al. [11] have shown that asthmatics experience blunted load perception when lower airway resistance is increased, particularly patients who have a low level of baseline lung function. Indeed, asthmatic children and adults with severe disease have been shown to have a reduced ability to detect oral threshold and resistive loads $[10,28]$ compared with a healthy control group. The asthmatic subjects in the current study were only mildly asthmatic and were asymptomatic at the time of the study. Since they did not have persistent lower airway obstruction, they may not yet have developed impaired load perception.

Finally, heightened sensitivity to an increase in nasal resistance (as with the application of a progressive nasal load) may actually contribute to a worsening of asthma. Slight increases in nasal resistance may cause asthmatic subjects to prematurely switch to oral route breathing, thus bypassing the airconditioning and filtering functions of the nose. This may result in the introduction of unfiltered, nonconditioned air into the lower airways, with possible drying of the airways and induction of a scenario of worsening asthma similar to the mechanisms involved in exercise-induced asthma. Cooler, dryer air entering the lower airways causes desiccation of the liquid lining the airways precipitating the release of inflammatory cell mediators and the subsequent development of an asthmatic response [29]. This may represent an important mechanism in the pathway to the development of chronic asthma.

In conclusion, the present study is the first to examine the propensity for externally applied nasal loads to initiate a switch in breathing route. Although graded inspiratory threshold nasal loading resulted in a switch from exclusive nasal to oronasal breathing in all subjects studied, the mild asymptomatic asthmatic subjects switched at a lower load than the healthy controls. Heightened sensitivity to nasal loading in mild asthmatic subjects may increase their susceptibility to switch from nasal to oral breathing, thus increasing their exposure to nonconditioned inhaled gas, which may potentially induce worsening bronchoconstriction. Given that the subjects in the present study did not have an abnormally high nasal airflow resistance, the potential for oronasal or indeed mouth breathing in the wider asthmatic patient group, where the prevalence of nasal airway disease is much higher, seems substantial.

\section{ACKNOWLEDGEMENTS}

The authors wish to thank K. Byth (Westmead Millennium Institute and Westmead Hospital, Wentworthville, NSW, Australia) for statistical advice and analyses. 


\section{REFERENCES}

1 Kairaitis K, Garlick SR, Wheatley JR, Amis TC. Route of breathing in patients with asthma. Chest 1999; 116: 1646-1652.

2 Mangla PK, Menon MP. Effect of nasal and oral breathing on exercise-induced asthma. Clin Allergy 1981; 11: 433-439.

3 Anderson SD, Daviskas E. The mechanism of exerciseinduced asthma is... J Allergy Clin Immunol 2000; 106: 453-459.

4 McFadden ER Jr, Nelson J, Skowronski ME, Lenner KA. Thermally induced asthma and airway drying. Am J Respir Crit Care Med 1999; 160: 221-226.

5 Saibene F, Mognoni P, Lafortuna CL, Mostardi R. Oronasal breathing during exercise. Pflugers Arch 1978; 378: 65-69.

6 Niinimaa V, Cole P, Mintz S, Shephard RJ. The switching point from nasal to oro-nasal breathing. Respir Physiol 1980; 42: 61-71.

7 Schultz EL, Horvath SM. Control of extrathoracic airway dynamics. J Appl Physiol 1989; 66: 2839-2843.

8 Wheatley JR, Amis TC, Engel LA. Oronasal partitioning of ventilation during exercise in humans. J Appl Physiol 1991; 71: 546-551.

9 Slavin RG. Upper respiratory tract. In: Weiss EB, Stein M, eds. Bronchial Asthma: Mechanisms and Therapeutics. 3rd Edn. Boston, Little, Brown and Company, 1993; pp. 533-544.

10 Fritz GK, McQuaid EL, Nassau JH, Klein RB, Mansell A. Thresholds of resistive load detection in children with asthma. Pediatr Pulmonol 1999; 28: 271-276.

11 Julius SM, Davenport KL, Davenport PW. Perception of intrinsic and extrinsic respiratory loads in children with life-threatening asthma. Pediatr Pulmonol 2002; 34: 425-433.

12 Eckert DJ, Catcheside PG, McDonald R, et al. Sustained hypoxia depresses sensory processing of respiratory resistive loads. Am J Respir Crit Care Med 2005; 172: 1047-1054.

13 Chen RC, Que CL, Yan S. Introduction to a new inspiratory threshold loading device. Eur Respir J 1998; 12: 208-211.

14 Borg GA. Psychophysical bases of perceived exertion. Med Sci Sports Exerc 1982; 14: 377-381.

15 Wheatley JR, Amis TC, Engel LA. Nasal and oral airway pressure-flow relationships. J Appl Physiol 1991; 71: 2317-2324.

16 Cole P. Upper respiratory airflow. In: Proctor DF, Andersen IB, eds. The Nose: Upper Airway Physiology and the Atmospheric Environment. Amsterdam, Biomedical Press, 1982; pp. 163-182.
17 Syabbalo NC, Bundgaard A, Entholm P, Schmidt A, Widdicombe JG. Measurement and regulation of nasal airflow resistance in man. Rhinology 1986; 24: 87-101.

18 Laine MT, Warren DW. Perceptual and respiratory responses to added nasal airway resistance loads in older adults. Laryngoscope 1995; 105: 425-428.

19 Nishino T, Kochi T. Breathing route and ventilatory responses to inspiratory resistive loading in humans. Am J Respir Crit Care Med 1994; 150: 742-746.

20 Ward KA, Nicholls DP, Stanford CF. The prevalence of preferential nasal breathing in adults. Respir Med 1993; 87: 295-297.

21 Warren DW, Hairfield WM, Dalston ET. Nasal airway impairment: the oral response in cleft palate patients. Am J Orthod Dentofacial Orthop 1991; 99: 346-353.

22 Harding R, Hooper SB, Wood GA. Initiation of oral breathing in lambs in response to airway obstruction: mechanisms. J Appl Physiol 1991; 71: 1574-1580.

23 Orani GP, Anderson JW, Sant'Ambrogio G, Sant'Ambrogio FB. Upper airway cooling and l-menthol reduce ventilation in the guinea pig. J Appl Physiol 1991; 70: 2080-2086.

24 Wheatley JR, Amis TC, Engel LA. Influence of nasal airflow temperature and pressure on alae nasi electrical activity. J Appl Physiol 1991; 71: 2283-2291.

25 Sekizawa SI, Tsubone H. Nasal receptors responding to noxious chemical irritants. Respir Physiol 1994; 96: 37-48.

26 Gozal D, Omidvar O, Kirlew KA, et al. Identification of human brain regions underlying responses to resistive inspiratory loading with functional magnetic resonance imaging. Proc Natl Acad Sci USA 1995; 3: 6607-6611.

27 Eckert DJ, Catcheside PG, Smith JH, Frith PA, McEvoy RD. Hypoxia suppresses symptom perception in asthma. Am J Respir Crit Care Med 2004; 169: 1224-1230.

28 Kifle Y, Seng V, Davenport PW. Magnitude estimation of inspiratory resistive loads in children with life-threatening asthma. Am J Respir Crit Care Med 1997; 156: 1530-1535.

29 Anderson SD, Rodwell LT, Daviskas E, Spring JF, du Toit J. The protective effect of nedocromil sodium and other drugs on airway narrowing provoked by hyperosmolar stimuli: a role for the airway epithelium? J Allergy Clin Immunol 1996; 98: S124-S134. 